\title{
VERSITA
}

\section{Shock Therapy - Rethinking the Global Order}

\author{
Chandran Nair ${ }^{*}$ \\ 1 Global Institute for Tomorrow, Suite 1111, Cityplaza One, 1111 King's Road, Taikoo Shing, Hong Kong
}

\section{KEYWORDS}

Capitalism

Consumerism

Globalisation

Global economy

Governance

Lifestyle

Poverty

Environmental

degradation

Sustainability

Resource constraint

Market inefficiencies

\section{ABSTRACT}

The most obvious lesson from the recent crisis is that today's version of unfettered capitalism is unable to selfcorrect. For the past 30 years and more, perhaps, the neoliberal model of capitalism has ruled supreme, promoting ultimate freedom in markets and the globalisation of finance to apparently deliver endless prosperity to all through consumption-led growth. The result has been massive environmental damage, depletion of natural resources and a growing gap between rich and poor. The model is unravelling, as the hidden costs are surfacing everywhere. Asian governments are being called upon to wake up and understand that to rely on the market to correct the inefficiencies in the allocation of resources is at best futile and naive and at worst plain dishonest.

\section{Introduction}

In the West, it started with the financial crisis originating in the US. More recently the debt issues in Greece and other European countries have put paid to the alleged stability of the euro zone. In London, a sense of entitlement and moral decay triggered aimless violence and looting. Asia, often seen as the deus ex machina of the global economy because of its potential markets (mega-consumption), the cost of the boom is most visible in ravaged landscapes, a highly degraded environment, the rapid depletion of resources and the erosion of the most basic of social nets. And Asia has

\footnotetext{
* Contact address: cnair@global-inst.com (C. Nair)
} 
not even started. All of this, if one is honest, has its origins in the almost religious belief in the West that took hold globally in the last three decades: that ultimately free markets, technology, finance and democracy can offer everyone every freedom and solve all the problems of the world. It is time for a hard rethink.

The most obvious lesson from the recent crisis is that today's version of unfettered capitalism is unable to self-correct. In financial markets, mathematical modelling was found to be so complex during the crisis of 2008 that even financial experts and senior bankers were at a loss when it came to clearing out the rot. The market became difficult to regulate, giving rise to the by now hackneyed expression 'too big to fail'. Too few people knew how it worked in the first place. The ones who did know had a vested interest in keeping it going. Unable to come to grips with the entanglements of decades' worth of financial hanky-panky, and usurped by those vested interests, regulators more or less threw in the towel. The only way to change the course of the dominant economic model at this point is to have an honest debate about capitalism in its current incarnation. It needs to be rid of its excesses and its strengths must be built upon, and Asia is perhaps best placed to lead the way.

\section{Strong medicine}

To get anywhere, however, Asia will need to reject the growth-at-all-cost model that hinges on encouraging relentless consumption. This growth paradigm, which thrives on under-pricing externalities, was fostered at the time of the Industrial Revolution, and then extended worldwide via colonialism. Then came the mantra of free markets and rejection of any suggestion that growth could reach a limit.

As the conditions for poverty are now better understood, Asian governments are being called upon to wake up and understand that to rely on the market to correct the inefficiencies in the allocation of resources is at best futile and naive and at worst plain dishonest. The rampant profiteering 
and volatile nature of financial markets, where decisions taken today can have direct consequences on public policy decisions in the future, means that access to basic rights cannot be left solely to the dictates of the supposed free markets. Asian governments will also need to reject the notion that wealth will trickle down by some ethereal gravity and that this is the only way to create more equitable and prosperous societies. These objectives should be without question the responsibility of governments and not abdicated to free markets and its agents. If Asian government's follow this path, then the majority of their populations - which make up the majority of the world's poor - will suffer dire consequences. To change course they will need to be bold and take on vested interests making this the political challenge of the $21^{\text {st }}$ century.

The consumption-led growth model is well past its sell-by date. In fact, one could go as far as characterising the current challenges facing capitalism as equivalent to the death throes of a sick man: one born in an era of privilege, of abundance, global dominance of a minority and thus accustomed to consuming too much. The tools to correct the inherent market failures need to be redesigned to compute the true cost of resources to produce the goods and services that drive the global economy. Western nations find this transition very difficult and thus hope for some international consensus in the matter, but this is based on rules the developing nations of the world were not the authors of. This is often an attempt to shift responsibility, whilst at the same time looking to and inherently expecting Asian economies to continue to subscribe to and fuel the old model.

The developing world, intellectually subservient for the last few centuries, has sadly sought to ape and emulate this model and thereby unwittingly helped bring the harsh realities of this model to the fore. Asian governments for their part will therefore find it extremely difficult to reshape the expectations of billions who have been told they can have it all, too. But the great opportunity lies in the fact that the majority have not yet been accustomed to even the most basic of consumption needs taken for 
granted in the West. Thus Asian governments, if they are bold enough, can seize the opportunity to meet the most basic needs of the majority and thereby also ensure their legitimacy whilst reshaping capitalism and maybe even saving the planet.

\section{Eating the planet}

Imagine the world by 2050, in which up to five billion Asians are consuming like modern day Americans. As Asia's global prominence increases, so too will its population's expectations. The two billion Asians at the margins of the consumption economy will radically transform global demand and supply, not only for non-renewable commodities such as oil and coal (pumping their respective carbon emissions into the atmosphere), but also for renewable ones such as food (think meat consumption). This is no Malthusian rehash. China is already the world's largest car market and many hope that India will follow suit. Chinese current car ownership is about 150 per 1000 people and in India it is only about 30 per 1000. This compares with an average of 750 cars per 1000 people in the OECD countries.

Europeans need to embark on an open and radical debate with Asia about the real benefits and pitfalls of the current growth model and how it should be restrained to be sustainable. To do so would mean to rock the conventional Western wisdom of free market liberalism and force public policy makers to question the ultimate objectives of the drivers of economic growth and address an inefficient system of resource allocation, which does not truly reflect the real cost and pricing of externalities. Europe and Asia will need to lead this effort as it is unclear if America's politics of denial are ready for this shift.

A key issue is to acknowledge that technology cannot be expected to tackle the resource depletion and environmental impacts that growth 'for growth's sake' will have on the planet. This is why Asian government leaders must avoid aping the West and instead redefine the agenda to 
confront the ultimate challenge of how a global economy for 9 billion people in 2050 should operate within ecological limits. Resorting to the West's rhetoric about green solutions only highlights the current lack of boldness and intellectual honesty. But why does it persist? First, it perpetuates the belief that technology alone, with its money-making potential, can provide all the solutions and create win-win solutions. This is the rallying cry of the business-as-usual advocates. Second, these conventional solutions allow politicians and business leaders to avoid addressing the difficult political solution of introducing rules that would change how people behave and consume.

The impacts of two centuries of industrialisation and unfettered access to global resources, otherwise known as colonialism, resulted in an entrenched but false sense of the nature of progress, in addition to fuelling rampant consumption using under-priced or even free resources. A key belief is that without visible developments in technology and innovations in finance to facilitate globalisation, the global economy will become stagnant and worse regress or become atrophied. Not factored into this is the fact Asia may have more than five billion people by 2050 and with economic growth rates averaging five percent, its GDP is projected to grow to USD 230 trillion from its current USD 30 trillion. Those who refuse to acknowledge that this will have very severe consequences for the world are strictly in denial.

\section{Real competition}

Research has shown that wealthy-world democracies are in general more likely to reach and sign international environmental agreements than developing countries. But they are also more resistant to change than Asia. Bringing US petrol taxes into line with those of Europe is politically unthinkable. A sharp fuel tax rise in China might result in protests, but at least it's possible to envisage the government taking such a step. All of this points to the emergence of a new geopolitical reality that goes well beyond 
today's concerns about resource competition and potential conflicts. The failure of the Copenhagen climate change conference in 2009 and the total lack of progress since the adoption of the Kyoto Protocol in 1997 point to this, and make it hard to see how the world will reach a consensus on global warming let alone other resource-related issues.

The current concerns and challenges around the global production and access to rare earth elements is another case in point. In recent years much of the blame for this impasse on international agreements has been laid at the feet of newly emerging economies, especially China. Many other Asian, African and Latin American countries find themselves at loggerheads with the West's approach to international cooperation. Part of the problem is that many of these international frameworks are steeped in a relatively old world-view, whereby developed nations are accustomed to framing the parameters of such discussions. But expanding political and economic visibility of Asian countries on the world stage means this framework is beginning to produce a flurry of diminishing returns and only hinders diplomatic efforts to find solutions. It is unlikely the West will give up its powers as easily as some commentators suggest - the recent selection of the new IMF chief being a case in point. Asia will need to challenge conventional thinking and vested interests that suggest international cooperation is the only route to resolving global challenges, and that poverty and unemployment will be inevitable if they embark on a new course.

\section{Asia's new responsibility}

In light of this, Asian countries need to take action at home first and act unilaterally if needed. After all, many of these nations have a great deal of work to do in their own respective countries before they embark on being signatories to vast international schemes that often lay dormant after signing. Asia can start by setting limits on various forms of consumption through policy.

This means shaping policies around the following core principles: 
- Resources are limited: economic activity must be subservient to maintaining the vitality of resources;

- Resource use must be equitable for current and future generations: collective welfare must take priority over individual rights;

- Resources must be re-priced and productivity efforts should be focused on reducing use of resources and not of people, i.e. using less material with more people working.

Two key mechanisms that governments in Asia must use are pricing and limits. Industry needs a reality check. By imposing taxes and fees and removing subsidies in all parts of the value chain, governments can include ecological and social externalities in the price of goods and put a real price on the goods and services provided by the environment, an area where industry has been given a free ride for the most part so far. Taxing emissions is another key constraint on the impulse to burn up the planet's resources, and imposing fees for use of critical resources such as water and minerals. Caps will also have to be placed on resources, even bans, where appropriate. Tough action must be taken on forests and fisheries, and the fight here will also be against corruption. Relying on the markets to do the hard work is a failed ideological premise promoted by the West.

These actions will have a direct impact on the most egregious forms of consumption. Setting limits will force companies to adapt to a new type of resource pricing and consumer reality. Most importantly, it will begin to change behaviours and expectations whilst allowing more people to have a fairer share of limited resources. Examples would include how land, water and biodiversity is distributed, used, priced in relation to promoting industrial agriculture and food production, so that the oil-palm-based cookie is no longer exaggeratedly under-priced.

\section{Real co-operation}

European governments can play a vital role as agents of change, but they must first and foremost be intellectually honest and bold and openly 
acknowledge that it will be impossible to support such demands for material consumption, because it will irreversibly modify the planet's climate and resource pool, which in turn will create great suffering for many in Asia and even resource-rich Africa. Ultimately, it will have dire consequences for Europe not only in terms of its own resources, but also socially and politically. More honest forums involving Europe and Asia are necessary to address how to live within limits and constraints, rather than more tradedriven (though important) conferences and fairs that are essentially geared towards selling Asians technology and all sorts of goods to emulate European lifestyles, whilst allegedly also going 'green'.

European leaders must understand that Western-based solutions drawing on economic instruments such as emissions trading are not the panaceas they are made out to be. For Asia, the key instruments will have to be tough domestic policy choices that focus on strict resource management. This may include draconian regulations and even bans. Without such fundamental policy shifts to reflect the realities of resource under pricing in a crowded planet, shortages will push up commodity prices and cause many crises involving water, fisheries, forests, land use rights, housing and so forth. The next step, as history has showed us over and over again, will be social injustices and political upheavals.

Western intellectual domination has shaped Asian development and created a political and business culture in the region that now believes it is Asia's right to have a giant share of the global resource cake. The mere thought is patently absurd. The West chose its course essentially as the path of least resistance in a different era and the results are not all as rosy as the Western media and in particular the advertising industry would like to portray it. Business and political leaders in Asia, and consumers as well, can avoid the same mistakes as their Western counterparts and redirect the trajectory of growth and prosperity to focus on excellence in the basic rights to food, water, sanitation and health. These must be placed right at the heart of public policy - as opposed to an outdated form of economic policy. Everything else is just a recipe for complete havoc in the $21^{\text {st }}$ century. 


\section{Acknowledgement}

This article was first published under the title 'Shock Therapy' in Swiss Style. The Swiss Magazine for Leaders 224: 10-14, 2011.

\section{References:}

Nair, Chandran. 2011. Consumptionomics: Asia's Role in Reshaping Capitalism and Saving the Planet. Oxford: Infinite Ideas. 